\title{
PERANCANGAN APLIKASI TUTORIAL JURUS DASAR BELADIRI CIMANDE MENGGUNAKAN METODE PROTOTYPE
}

\author{
DIMAS ABISONO PUNKASTYO \\ Staf Pengajar Fakultas Teknik Prodi Teknik Informatika \\ Universitas Pamulang, Tangerang Selatan, Banten \\ Email:dimasabisono@gmail.com
}

\begin{abstract}
ABSTRAK
Ilmu beladiri adalah ilmu untuk kesejahteraan dunia dan akhirat yang berdasarkan prinsip prinsip beladiri, yaitu membela diri sendiri, dan bila mampu juga dapat membela orang lain. Apalagi dewasa ini sering terjadi tindakan kriminal yang disertai kekerasan di sekitar kita, mengaharuskan setiap orang mempunyai dasar ilmu beladiri. Indonesia memiliki banyak aliran ilmu beladiri, salah satunya adalah Tapak Suci yang sudah tergabung ke dalam organisasi Ikatan Pencak Silat Indonesia (IPSI). Cimand merupakan beladiri Indonesia yang tidak saja menekankan daya gunanya pada perkelahian semata, namun juga menekankan daya guna yang sama kuat dalam hal seni. Di Ekstrakurikuler Cimande MANLeuwiliang masih banyak siswa yang kesulitan dalam menghafal jurus - jurus dasar. Selain itu waktu pertemuan yang terbatas dalam latihan rutin menjadi hambatan bagi siswa, maka siswa harus mencari mediapembelajaran tambahan agar bisa berlatih di rumah. Untuk itu diperlukan perancangan aplikasi tutorial jurus dasar Cimande menggunakan smartphone berbasis android.

Dengan perancangan aplikasi yang berjalan di smartphone sehingga bisa diakses dimana saja. Kelebihan lain yaitu aplikasi ini bisa menjadi media pembelajaran yang praktis dan mudah dibawa. Selain itu, media pembelajaran yang dihasilkan juga lebih menarik dengan tambahan gambar dan video. Diharapkan aplikasi ini bisa efektif karena smartphone menjadi teknologi yang banyak digunakan masyarakat sekarang ini bahkan hampir menjadi kebutuhan pokok. Smartphone kebanyakan memiliki sistem operasi android yang menyediakan platform terbuka bagi para pengembang untuk menciptakan aplikasi mereka sendiri.
\end{abstract}

Keywords: Ilmu Beladiri, Aplikasi, Tutorial, Smartphone, Android.

\section{PENDAHULUAN}

Dewasa ini sering terjadi tindakan kriminal disertai kekerasan di jalanan. Untuk itu diperlukannya beladiri. Karena disadari ataupun tidak, setiap waktu kita memerlukan beladiri (SH, Suwaryo, 2008). Ilmu beladiri telah lama dikenal oleh bangsa Indonesia bahkan berpuluh - puluh tahun sebelum Indonesia merdeka, nenek moyang kita telah mampu meletakan dasar-dasar keilmuan beladiri (Irsyad, Muhammad Barie, 2008).

Tidak dipungkiri jika aplikasi berbasis android sangatlah banyak, dengan berbagai macam konten yang tersedia di dalamnya. Penggunaan smartphone selain sebagai media komunikasi, juga menjadikanya sebagai media pembelajaran (Melian, Lusi, 2012). Penggunaan smartphone untuk media pembelajaran beladiri membuat proses belajar bisa lebih cepat dipahami siswa.
Kecanggihan smartphone dibandingkan handphone cellular terletak pada system operasi yang tangguh, kecepatan proses yang tinggi, perangkat multimedia yang mutakhir, koneksi internet terbaik dan layar sentuh (Yanti, Eva, 2011). Karena smartphone mempunyai sistem operasi android sehingga penggunaan aplikasinya juga bisa digunakan di mana saja, kapanpun, dan konten yang diperlukan oleh pengguna bisa diakses dengan mudah (Herdiansyah, Muhammad Yanyan, 2013). Selain itu pengenalan beladiri Cimande kepada masyarakat khususnya siswa bisa lebih mudah dilakukan. Karena kini banyak siswa yang beralih menggunakan smartphone android untuk dijadikan sebagai media untuk mengakses informasi secara mudah dan cepat (Juraman, Stefanus Rodrick, 2014).

Di Estrakurikuler Cimande MAN Leuwiliang Kab. Bogor masih banyak siswa yang mengalami kesulitan dalam menghafal 
jurus-jurus dasar. Media yang tersedia untuk pengenalan beladiri ini kepada umum juga masih kurang, yang menjadikan kurang berminatnya siswa mengikuti kegiatan ini. Padahal semua orang membutuhkan beladiri. Karena semakin maraknya tindak kriminal yang disertai kekerasan, maka setiap orang wajib menguasai dasar beladiri untuk minimal bisa melindungi dirinya sendiri. Namun keterbatasan waktu latihan yang diadakan Ekskul Cimande MAN Leuwiliang Kab. Bogor menjadi hambatan belajar para siswa. Sehingga menu latihan yang didapat siswa tidak cukup banyak dan akhirnya siswa menjadi lambat menguasai beladiri. Karena waktu latihan rutin hanya $2 \mathrm{x}$ dalam seminggu, maka sering terjadi siswa yang tidak mengingat materi yang sudah diajarkan pada pertemuan sebelumnya.

Masalah yang digunakan untuk menyelesaikan permasalahan sistem pembelajaran antara lain dengan menggunakan model prototype (Widayat \& Dely, 2012), kelebihan model ini adalah Menghemat waktu pengembangan, Adanya komunikasi yang baik antara pengembang dan pelanggan, Pengembang dapat bekerja lebih baik dalam menentukan kebutuhan pelanggan. Sedangkan kelemahan model ini adalah teknik dan tools yang tidak optimal dan sulitnya pemeliharaan/ pengembangan sistem itu sendiri (Pressman, 2002). Model waterfall (Rynto, 2014) Kelebihan model ini adalah Mudah diaplikasikan, Memberikan template tentang metode analisis, desain, pengkodean, pengujian, dan pemeliharaan, Cocok digunakan untuk

produk software yang sudah jelas kebutuhannya di awal, sehingga minim kesalahannya. Sedangkan kelemahannya adalah diperlukan majemen yang baik, karena proses pengembangan tidak dapat dilakukan secara berulang sebelum terjadinya suatu produk. Dan model spiral / Incremental (Pressman, 2002), Kelemahan model ini adalah sulitnya meyakinkan user bahwa pendektan evolusioner bisa dikontrol.

Penelitian ini menerapkan model

prototype untuk proses pembelajaran, yang bertujuan untuk menyediakan alat bantu yang lebih interaktif bagi siswa dalam pembelajaran beladiri Cimande dan agar proses pembelajaran tidak terbatas dengan waktu, bisa dilakukan dimana saja dan kapan saja. Protoype adalah metode untuk mengotomatisasi fase definisi dan analisis, jadi merupakan bagian CASE (Computer Aided Software Enginering) tetapi prototype memberikan masukan pada tingkatan, kelebihannya adalah menghasilkan syarat yang lebih baik dari produksi yang dihasilkan oleh metode spesifikasi tulisan. User dapat mempertimbangkan sedikit perubahan selama masih berbentuk prototype, memberikan hasil yang akurat dari pada perkiraan sebelumnya, karena fungsi yang diinginkan dan kerumitannya sudah dapat diketahui dengan baik.

Berdasarkan permasalahan di atas, karya ilmiah ini mencoba membuat suatu aplikasi tutorial jurus dasar beladiri Cimande yang mudah diakses masyarakat umum khususnya anggota Ekskul Cimande MAN Leuwiliang Kab. Bogor. Agar dikemudian hari banyak orang yang menguasai beladiri untuk mengurangi kejahatan, dan cimande bisa dilestarikan sebagai warisan budaya Indonesia. Oleh karena itu, saya membuat karya ilmiah yang berjudul "PERANCANGAN APLIKASI TUTORIAL JURUS DASAR BELADIRI CIMANDE MENGGUNAKAN METODE PROROTYPE"

\section{METODE PENELITIAN}

Menurut (Pressman, 2010) Sering kali pelanggan hanya mendefinisikan serangkaian tujuan umum perangkat lunak yang akan digunakan, tetapi tidak mengidentifikasikan kebutuhan secara rinci untuk fitur dan fungsi. Sedangkan di sisi lain, pengembang tidak yakin dengan efisiensi Algoritma, kemampuan beradaptasi dari sistem operasi atu bagaimana seharusnya interaksi antara manusia dengan komputer. Dengan Model Prototyping pengembang dan pelanggan dapat saling berinteraksi mengenai sistem yang akan dibangun ketika persyaratan tidak jelas. 


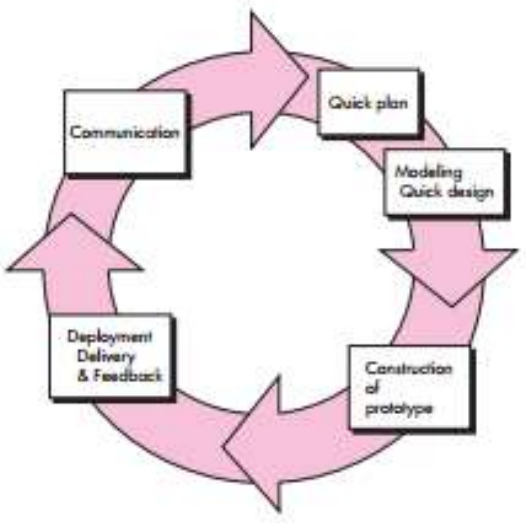

Gambar 1. Model Prototype menurut Presman

Tahap-tahap pengembangan Protoype model menurut Rogeer S. Pressman:

\section{a. Communication}

Pada tahap ini pengembang dan pelanggan bertemu dan saling berinteraksi mendefinisikan tujuan dari perangkat lunak yang akan dibuat.

b. Quick Plan, Modelling dan Quick Design

Tahap ini dilakukan setelah gambaran perangkat lunak secara umum diketahui. Quick Design fokus terhadap perancangan antar muka atau bagaimana output dari perangkat lunak.

\section{c. Construction of Prototype}

Setelah diketahui tujuan umum dan rancangan dari perangkat lunak, maka prototype mulai dikerjakan.

\section{d. Deployment Delivery and Feedback}

Setelah Prototype selesai maka prototype tersebut diserahkan kepada pelanggan untuk di evaluasi. Pada tahap ini pelanggan dapat mengetahui apakah perangkat lunak sudah sesuai dengan kebutuhan dengan memberikan feedback. Pengembang dapat mengetahui apa yang harus diperbaiki dari prototype yang telah dibuat berdasarkan feedback dari pelanggan. Seiring dengan telah dievaluasinya prototype perangkat lunak oleh pelanggan, tahap Communication kembali terulang dilanjutkan dengan tahap-tahap berikutnya hingga kepuasan pelanggan terhadap perangkat lunak yang dibutuhkan tercapai.

\subsection{Metode pengumpulan data}

Pengumpulan data-data yang diperlukan dilakukan dengan beberapa cara, yaitu:

a. Studi pustaka

Dilakukan dengan cara membaca referensi yang berkaitan dengan masalah yang berkaitan dengan aplikasi android dan web.

b. Studi lapangan (observasi)

Dilakukan dengan cara pengamatan langsung terhadap kegiatan penyewaan lapangan futsal.

c. Wawancara / Interview

Pengumpulan data dilakukan dengan cara bertatap muka langsung dan melakukan tanya-jawab pada pihak terkait yaitu petugas lapangan futsal.

\subsection{Metode Pengembangan Sistem}

Model Prototype adalah salah satu pendekatan dalam rekayasa perangkat lunak yang langsung mendemonstrasikan bagaimana sebuah perangkat lunak atau komponek-komponen perangkat lunak akan bekerja dalam lingkungannya sebelum tahapan konstruksi aktual dilakukan (Howard, 1997).

\section{PEMBAHASAN}

Tahap implentasi adalah tahap penerapan sistem aplikasi tutorial jurus dasar beladiri cimande dengan menggunakan program androind studio dengan bahasa pemrograman Java. Tahap implementasi merupakan tahap lanjutan dari perancangan sistem yang akan dilakukan jika sistem disetujui, termasuk program yang sudah dibuat agar siap untuk dioperasikan secara optimal, dengan menerapkan perancangan antarmuka ke dalam bentuk halaman utama beserta ruang lingkup aplikasinya.

Setelah proses kompilasi pada logika program telah berhasil dan tidak ada lagi pesan kesalahan maka hasilnya dapat dilihat pada emulator android. Kemudian langkah selanjutnya yaitu mengimplementasikan aplikasi tutorial jurus dasar beladri cimande pada smartphone.

Menu web home ini adalah halaman utama setelah aplikasi terbuka yang berisi logo dari aplikasi dan menu. Berikut adalah bentuk tampilan program yang telah dibuat: 

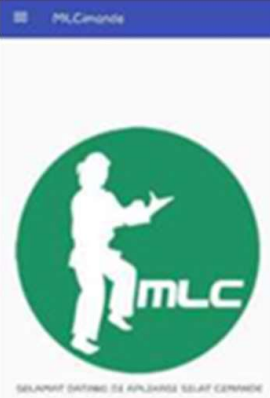

\section{Gambar 2 Halaman Home}

Drawer Menu akan tampil ketika user mengklik tombol garis tiga (Hamburger Button) di pojok kiri atas, drawer menu berisi menu-menu yang bisa dipilih oleh user. Memiliki 4 menu yang berisi menu pengenalan, jurus, tentang dan bantuan:

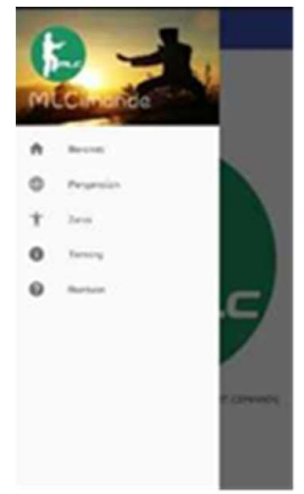

\section{Gambar 3 Halaman Drawer Menu}

Halaman pengenalan adalah menu petama dalam drawer menu halaman ini berisikan tentang sejarah singkat, tujuan dan sumpah silat cimande.

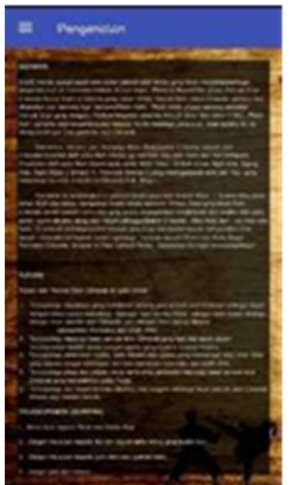

Gambar 4 Halaman Pengenalan
Halaman daftar jurus merupakan menu kedua di dalam drawer menu. Halaman ini berisi daftar jurus silat cimande. Untuk melihat isi dari jurus, user bisa memilih salah satu dari daftar jurus.

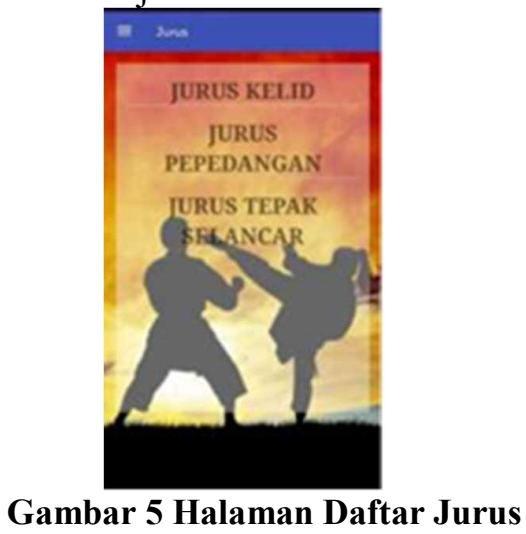

Halaman ini akan muncul ketika user memilih salah satu dari daftar jurus. Halaman ini berisikan tentang tutorial dasar dari jurus silat Cimande.

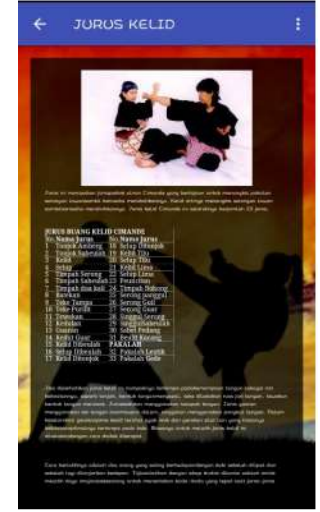

\section{Gambar 6 Halaman Jurus Kelid}

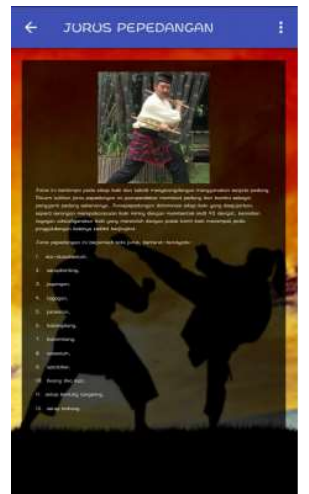

Gambar 7 Halaman Jurus Pepedangan 


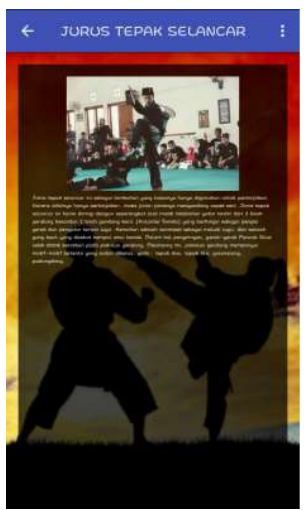

Gambar 8 Halaman Jurus Tepak Selancar

Tampilan ketika klik button video di bagian kanan atas dari halaman jurus, user akan dialihkan keluar aplikai dan secara otomatis membuka aplikasi youtube. Dalam video ini terdapat tutorial lengkap dari jurusjurus silat Cimande.

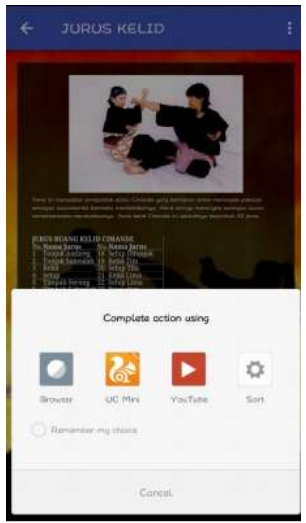

Gambar 9 Tampilan ketika klik button video

Pada tampilan halaman Tentang berisikan logo dari aplikasi dan informasi tentang pengembang.

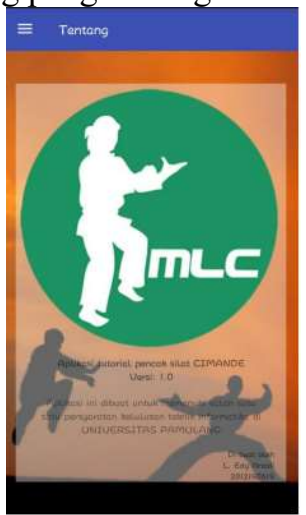

Gambar 10 Halaman Tentang
Halaman Bantuan berisikan panduan penggunaan aplikasi secara sederhana.

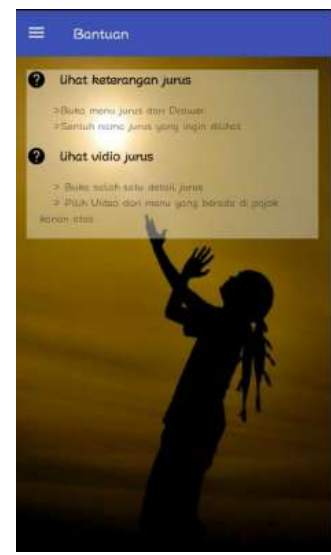

Gambar 11 Halaman Bantuan

\subsection{Pengujian}

1. Pengujian BlackBox

Pengujian black box memfokuskan pada keperluan fungsional dari software. Karena itu uji coba blackbox memungkinkan pengembang software untuk membuat himpunan kondisi input yang akan melatih seluruh syarat-syarat fungsional suatu program.

Tabel 1. Pengujian Black Box

\begin{tabular}{|l|l|l|}
\hline Kelas Uji & $\begin{array}{l}\text { Detail } \\
\text { Pengujian }\end{array}$ & Jenis Uji \\
\hline $\begin{array}{l}\text { Button } \\
\text { Menu }\end{array}$ & $\begin{array}{l}\text { Menampilkan drawer } \\
\text { menu }\end{array}$ & Black Box \\
\hline $\begin{array}{l}\text { Menu } \\
\text { Pengenal }\end{array}$ & $\begin{array}{l}\text { Menampilkan } \\
\text { Menu }\end{array}$ & Black Box \\
\hline $\begin{array}{l}\text { Menu } \\
\text { Jurus } \\
\text { nonow }\end{array}$ & $\begin{array}{l}\text { Menampilkan menu } \\
\text { jurus dasar Beladri } \\
\text { Menand }\end{array}$ & Black Box \\
Menu & $\begin{array}{l}\text { Menampilkan menu } \\
\text { Tentang }\end{array}$ & Black Box \\
\hline $\begin{array}{l}\text { Menu andikasi } \\
\text { Help }\end{array}$ & $\begin{array}{l}\text { Menampilkan menu } \\
\text { help }\end{array}$ & Black Box \\
\hline
\end{tabular}

\section{Pengujian Kinerja Aplikasi}

Pengujian kinerja aplikasi dilakukan kepada 30 anggota dan pengurus Cimande MAN Leuwiliang Kab. Bogor, dengan mencoba langsung aplikasi. Setelah responden mencoba aplikasi, peneliti membagikan instrumen kuisioner untuk 
menilai apakah setuju jika aplikasi ini membantu para anggota baru untuk lebih cepat dalam memahami jurus- jurus dasar atau tidak.

Adapun pertanyaan yang dipersiapkan untuk kuisioner adalah sebagai berikut:

1. Materi bermanfaat.

2. Materi sesuai kebutuhan.

3. Tampilan aplikasi mudah dioperasikan.

4. Tampilan aplikasi mudah dipahami.

5. Tampilan aplikasi efektif.

6. Tampilan aplikasi jelas.

7. Tampilan aplikasi menarik

Nilai total yang didapatkan yaitu 539, sedangkan nilai maksimal untuk tiap pertanyaan adalah 3 (Sangat Setuju), sehingga dapat diperoleh nilai total maksimal adalah 630. Nilai maksimal tersebut diperoleh dari hasil perkalian jumlah responden, jumlah pertanyaan, dan nilai maksimal tiap pertanyaan yaitu $30 \times 7 \times 3=630$.

Setelah menentukan nilai maksimal, maka untuk persentase kelayakan secara keseluruhan adalah sebagai berikut:

$$
\begin{aligned}
& \begin{array}{l}
\text { Persentase kelayakan (\%) } \\
\text { skor yg di observasi }
\end{array} \\
& =\frac{\text { skor ya diharapkan X } 100 \%}{539} \\
& =\frac{-}{630} \times 100 \%=85,5
\end{aligned}
$$

Dari skor tiap pertanyaan yang dipilih oleh responden pengguna di atas, memberikan skor 85.5. Hal ini menandakan bahwa:

1. Responden setuju bahwa aplikasi Cimande memberikan materi yang bermanfaat.

2. Responden setuju bahwa aplikasi Cimande memberikan materi sesuai kebutuhan

3. Responden setuju bahwa tampilan aplikasi Cimande mudah dioperasikan.

4. Responden setuju bahwa tampilan aplikasi Cimande mudah dipahami.

5. Responden setuju bahwa tampilan aplikasi Cimande efektif.

6. Responden setuju bahwa tampilan aplikasi Cimande jelas.

7. Responden setuju bahwa tampilan aplikasi Cimande menarik.

\section{KESIMPULAN}

Hasil akhir dari karya ilmiah ini, dapat ditarik kesimpulan bahwa sistem aplikasi tutorial ini dapat digunakan sebagai media pembelajaran siswa pemula Cimande secara mandiri. Dalamsistem ini dapat memberikan suatu informasi tentang Cimande dan materi materi pembelajaran jurus dasar, sehingga siswa pemula bisa lebih cepat dalam menguasai jurus dasar.

Berdasarkan hasil kuesioner yang diadakan kepada pengurus dan anggota Cimande MAN Leuwiliang Kab. Bogor Diperoleh hasil sebesar $85,5 \%$ dari 30 responden menyatakan setuju, bahwa dengan adanya aplikasi bisa membantu siswa pemula Cimande dalam proses pembelajaran jurus dasar menjadi lebih mudah dan cepat untuk dikuasai dibandingkan dengan tanpa bantuan aplikasi ini. Siswa yang menggunakan aplikasi ini bisa menguasai jurus dasar dalam waktu 2 minggu, sedangkan siswa tanpa bantuan aplikasi ini menguasai jurus dasar dalam waktu 4 minggu. Dengan bantuan perangkat android yang bisa digunakan dimana saja dan kapan saja, sehingga informasi dapat diperoleh dengan mudah, cepat, dan akurat.

Aplikasi ini dapat diakses oleh semua orang yang ingin mengetahui informasi tentang Cimande. Berdasarkan analisa dan juga pengujian yang dilakukan menggunakan Black Box bahwa secara fungsional aplikasi ini sudah menghasilkan hasil output yang diinginkan. Sistem yang diterapkan pada aplikasi ini pun telah siap mendukung kebutuhan untuk para pengguna dan juga Ekstrakurikuler Cimande MAN Leuwiliang Kab. Bogor.

\section{SARAN}

Berdasarkan evaluasi yang berjalan, penulis berharap agar aplikasi yang telah dibuat dapat bermanfaat dengan baik bagi para siswa Cimande. Untuk itu penulis mengusulkan beberapa saran antara lain:

1. Aplikasi ini masih membutuhkan penambahan tentang komponen jurus dasar Cimande.

2. Pada sistem penyimpanan aplikasi ini dapat dikembangkan menggunakan media 
penyimpanan database untuk dapat lebih tertata baik dalam tampilannya.

3. Mengembangkan aplikasi ini agar tidak hanya dapat dijalankan diperangkat berbasis android tetapi juga dapat dijalankan diperangkat lainnya.

\section{DAFTAR PUSTAKA}

1. Herdiansyah, Muhammad Yanyan. (2013). Kelebihan Smartphone. Pembangunan Aplikasi Bantu Dalam Menghafal AlQuran Berbasis Mobile, 1-2.

2. Irsyad, Muhammad Barie. (2008). Buku Panduan Seni Beladiri. Yogyakarta:Tapak Suci UMY.

3. Juraman, Stefanus Rodrick. (2014). Smartphone. Pemanfaatan Smartphone Android Oleh Mahasiswa Ilmu Komunikasi Dalam Mengakses Informasi Edukatif, 1-3.

4. Melian, Lusi. (2012). Penggunaan Smartphone. Aplikasi Mobile Piano, Gitar, dan Drum Berbasis Android, 1-4.

5. Pressman, R. S. (2010). Software Engineering : A Practicioner's Approach, 7th Edition. New York: McGraw-Hill Inc.

6. SH, Suwaryo. (2008). Pentingnya Beladiri. Peranan Organisasi Perguruan Beladiri Pencak Silat Dalam Meminimalkan Kejahatan, 2.

7. Yanti, Eva (2011). Kecanggihan Smartphone. Pemanfaatan Smartphone Dalam Pendidikan Keperawatan, 2. 